\title{
NEW EVOLUTIONARY TECHNIQUE FOR OPTIMIZATION SHUNT CAPACITORS IN DISTRIBUTION NETWORKS
}

\author{
Ali Elmaouhab - Mohamed Boudour — Rabah Gueddouche *
}

\begin{abstract}
The paper presents a new evolutionary technique for optimizing on one part the numbers, the sizes and locations of shunt capacitors in radial distribution network in away to minimize the annual cost of active power losses with the improvement of voltage profiles of different buses. The technique is applied on 10 buses network and on IEEE 34 buses network test. The results are compared with ones of previous studies using heuristiques methods and the same network tests.

K e y w or d s: evolutionary technique, genetic algorithm, radial distribution network, shunt capacitor placement
\end{abstract}

\section{INTRODUCTION}

It is known that the flow of reactive current in an electric network produces supplementary power loss and increases the voltage drop. Comparing to transport network, the distribution network have low voltage and a large current which produce the losses by Joule effects relatively higher than in the transport networks (more than $13 \%$ of the losses). To improve the load flow, the quality of energy and to avoid as well a new investment on building a new grid, we have to reduce the losses by installing shunt capacitors in the appropriate places. In the literature we can find many different optimization techniques in away to optimize locations, sizes and numbers of capacitors.

K. Prakash and M. Sydulu [8] have proposed an algorithm based on Particle Swam Optimization, a metaheuristic technique, for estimating the shunt compensation level necessary to improve the voltage level and reduce the active power losses. For finding the optimum placements they have used the loss sensibility factors.

M. D. Reddy and V. C. V. Reddy [4] have proposed a method with two levels to find the placement and the size of shunt capacitors. They used a fuzzy algorithm to search the optimal placement and real genetic algorithm to find the optimal size of capacitors.

R. S. Rao and S. V. L. Narasimham [3] have also presented a method with two levels. In the first level they have used the lost sensibility factors to search the appropriate buses which will receive the compensation capacitors. And in the second level they have used the Plant Growth Simulation Algorithm (PGSA) to determine the shunt compensation level at the placement of the optimal candidate in away to improve the voltage profile and to reduce the active power losses.

In this paper a new evolutionary technique is presented which perform the optimization of the number, size and the placement of the shunt capacitors in one part only (one level). These have lead to reduce the investment cost of new reactive energy sources and the active power losses with the voltage levels improvement.

\section{EVOLUTIONARY ALGORITHM}

The evolutionary algorithms are based on natural evolution process, particularly on living species evolution. It is composed of three mains elements [1]:

- A population which is composed by several individuals representing possible solutions.

- A mechanism of evaluation which express the adaptation of each individual of the population in his environment.

- A mechanism of evolution which is composed of several operators that allows to eliminate certain individuals and create new ones from selected individuals.

\section{POPUlATION AND CODING}

The population research methods are performed among the population constituted by several potential solutions. Generally, the size of the population is between 30 and 200 individuals. The individuals coding is an essential parameters for the method. They are represented in chain structure, as chromosomes, containing genes or characters of predetermined alphabet. There is different way for coding a solution. In our study, individual is represented by two parts of distinct chromosome. The first part receives only binary values for coding candidate position state. If the element in position $\mathrm{i}$ is equal to 1 then a capacitor is connected to the bus I. Otherwise, the bus does not receive a capacitor. The second part includes integer numbers which represent the battery size indices [2]. Each part of chromosomes has $N$ positions. $N$ represents the buses number of the network. The following figure gives an example of solution for a network with 9 buses.

\section{$[\underline{011001000 / 265114523}$ \\ Buses Size index}

Fig. 1. Chromosome coding

\footnotetext{
* Universite des Sciences et la Technologie Houari Boumedienne, Electrical Engineering Faculty, Laboratoire des Systémes Energitiques et Industriels, El Alia BP32 Bab Ezzouzr, Algeria, aelmaouhab@yahoo.fr, mboudour@IEEE.org, magic.elt@gmail.com
} 
Table 1. Capacitors data [10]

\begin{tabular}{ccc}
\hline Index & Capacitor size $(\mathrm{kVAr})$ & Price $(\$)$ \\
\hline 1 & 150 & 750 \\
2 & 300 & 975 \\
3 & 450 & 1140 \\
4 & 600 & 1320 \\
5 & 900 & 1650 \\
6 & 1200 & 2040 \\
\hline
\end{tabular}

From Table 1 , the buses 2, 3 and 6 receive capacitors respectively with size 1200,900 and $600 \mathrm{kVAr}$. The rest of buses will not get capacitors because their corresponding values in the first part of chromosomes are equal to zero. Thus, their number in the second part of chromosomes is ignored when calculating the prices and power losses.

Generally, an evolutionary algorithm start with an initial population most often generated at random [2], [5]. In our study we have generated the initial population in such manner to accelerate the convergence. The following steps show how the initial population is generated.

The total active power losses for a distribution network with $n$ buses is

$$
\operatorname{Ploss}_{T}=\sum_{i=1}^{n} I_{i}^{2} R_{i}
$$

$I_{i}$ and $R_{i}$ are respectively current and resistance of the line i.

By performing the load flow analysis we get the different currents on the network. As the current is composed of active current component $\left(I_{a}\right)$ and reactive current component $\left(I_{r}\right)$ we can rewrite (1) like

$$
\operatorname{Ploss}_{T}=\sum_{i=1}^{n} I_{a i}^{2} R_{i}+\sum_{i=1}^{n} I_{r i}^{2} R_{i} .
$$

To get the total power losses variation caused by the reactive load in bus $\mathrm{k}$, we first calculate the total losses without taking into account the reactive power of the load of the bus under study (bus $\mathrm{k}$ in this case) [6].

$$
\begin{aligned}
& \text { Ploss }_{T} \text { (before) }= \\
& \quad \sum_{i=1}^{n} I_{a i}^{2} R_{i}+\sum_{i=1}^{k}\left(I_{r i}-I_{r l k}\right)^{2} R_{i}+\sum_{i=k+1}^{n} I_{r i}^{2} R_{i} .
\end{aligned}
$$

$I_{r l k}$ : reactive current component of the load in bus $\mathrm{k}$.

Then by subtracting (3) from (2) we get the desired power variation.

$$
\Delta P \operatorname{Poss}_{T k}=2 I_{r l k} \sum_{i=1}^{k} I_{r i} R_{i}-I_{r l k}^{2} \sum_{i=1}^{k} R_{i} .
$$

This expression is based on the minimal path between the considered bus and the substation. By using the expression (4), the buses are stored in decreasing order in array named Target.

(A) For each individual:

- The total number capacitor $n_{\text {cap }}$ is generated by random function from 1 to $n$.
- The capacitors are placed at $n_{\text {cap }}$.

- The capacitors sizes indices are chosen at random from the data table starting from very sensitive bus.

The next bus, following the sensitivity order, should have an inferior index and so on till last bus. After performing the load flow analysis, the individual is accepted among the initial population if the voltage value of each bus satisfies the following constrain

$$
V_{\min } \leq V_{i} \leq V_{\max }
$$

$V_{i}$ is voltage value at bus $\mathrm{I}, V_{\min }$ and $V_{\max }$ are minimal and maximal voltage respectively of the network.

(B) If the individual number $n_{p}$, introduced by the user, is reached, the initial population is closed.

\section{EVALUATION PROCESS}

The evaluation is carried out using fitness function or adaptation function which is calculated for each individual of population. The unique difference between the two functions in our method is the inclusion of a constrain (minimization of capacitor quantity to be installed) in the fitness function as penalty coefficient $k_{\text {cf }}$ (fixed cost of capacitor placement).

$$
F i t=k_{p} \text { Ploss }_{T}+k_{e} \text { Eloss }_{T}+\sum_{i=1}^{m}\left(k_{\mathrm{cf}}+k_{i}^{c} Q_{i}^{c}\right) .
$$

$k_{p}$ Ploss $_{T}$ and $k_{e}$ Eloss $_{T}$ are total power losses cost and total energy loss cost respectively $k_{i}^{c} Q_{i}^{c}$ is the cost of power compensation installed in bus I.

\section{EVOLUTION PROCESS}

The stochastic optimization techniques are base on a balance between intensification of the research and its diversification. The intensification permits the research of better quality solutions basing on previous found solutions. And the diversification sets the strategies which allow to investigate a large space of solutions. If the balance is not observed, the convergence will move fast toward local minimums (without diversification) or a long investigation (without intensification).

\subsection{Parents Selection}

Among the individuals of the current population "old parent population" we choose:

- 01 individual (Parent $A$ ) who realize the minimum of the fitness function (Fit).

- 01 individual (Parent $B$ ) who realize the minimum of total active power losses $\left(\mathrm{Ploss}_{T}\right)$.

- 01 individual (Parent $C$ ) who realize the maximum of $\min (V)$.

Each of these individuals has the characteristics of the ideal individual researched by the algorithm. 


\subsection{Intermediate recombination}

The intermediate recombination is used specially in the evolution strategies. Contrary to crossover operators with $k$ points which exchange the information between parents, the intermediate recombination creates the descendants by balancing the components of several parents. From 3 parents selected from the current population we generate $n_{p}$ individuals, by using the data of figure1, as shown in Fig. 2.

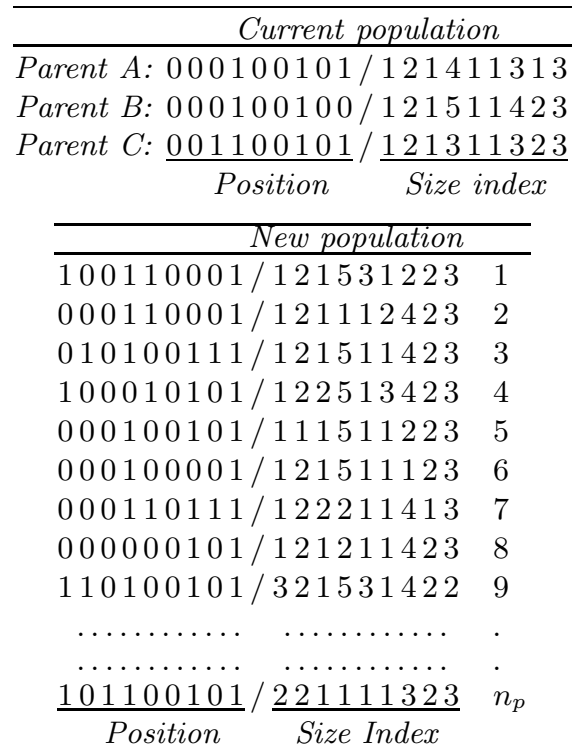

Fig. 2. Recombination procedure

The recombination procedure is presented in the following steps.

1. All individuals of the new population are formed from the first part of the chromosome of parent $A$ (positions) and from the second part of the chromosome of parent $B$ (size indices).

2. For each individuals of the new population:

- The total gene number $\beta$ for each part of imported chromosome from parent $C$ is chosen between 1 and $n$ with $\beta=n * T_{\text {div }}$.

- Each gene is chosen at random from parent $C$ (positions) and allocated to a random position in Indiv new (size indice).

- After having performed the load flow analysis, the individual is accepted in the new population if the voltage magnitude of each bus satisfies the inequality constraint (5)

3. The best individual, evaluated by the fitness function Fit between the current population and the new population, will compose the population which to be reproduced named "new parent population" and will replace "old parent population" for next generation (elitism strategy).

\section{PROPOSED ALGORITHM}

The method of the proposed algorithm is as follow: Step 1: Read the network data.

Initialize parameters.
Perform load flow analysis.

Step 2: Classify all buses on decreasing order in the array Target using expression (4).

Step 3: Generate the initial population using procedure defined in Section 3.

$\underline{\text { Step 4: }}$ Evaluate all individuals by using fitness function and chose 3 parents.

$\underline{\text { Step 5: }}$ If the generation number is less than Ngen then go to step 5.1

Else go to step 6.

Step 5.1: generate population with best found individuals new parent population using procedure defined in Section 5.

Step 5.2: Perform the load flow analysis and evaluate the individuals according to (6)

Step 5.3: If "new population parents" includes two identical individuals, chosen at random, then go to step 5.1 to generate "new population".

Else go to next step.

Step 5.4: choose 3 parents among "new parent population".

Step 6: choose the best individual among "new parent population" and display the results.

Table 2 presents the significant parameters which characterizes this algorithm.

Table 2. Control parameters

\begin{tabular}{ccl}
\hline Control parameters & Nature & Definition \\
\hline$n_{p}$ & Variable & $\begin{array}{l}\text { Individual number } \\
\text { in a population }\end{array}$ \\
$N_{\text {gen }}$ & Variable & $\begin{array}{l}\text { Maximal number } \\
\text { of generation }\end{array}$ \\
$\mu: 3$ & Fixed & $\begin{array}{l}\text { Number of parents } \\
\text { Pumbiation size }\end{array}$ \\
$\lambda: n_{p}$ & Relative & $\begin{array}{l}\text { Populatendants } \\
\text { of descendater }\end{array}$ \\
$T_{\text {div }}$ & Fixed & Balance rate \\
mut: auto-adaptable & Fixed & Mutation operator \\
$r e c:$ intermediate & Fixed & Combination operator \\
\hline
\end{tabular}

\section{APPLICATION}

In order to get an optimum solution several parameters have to be adjusted. The performance of genetic algorithms depends on the chosen values parameters.

In the presented algorithm, we have chosen the values of the control parameters after having done several tests which has yielded to the best optimization results. The obtained results have been compared with ones presented in [3], [4], [6], [7] and [8].

For comparison purposes, we kept same costs used in the compared papers.

The 10 buses test network used in [11] and [12] is a $23 \mathrm{kV}$ radial distribution network without ramification. The network data is given in the Tab. 8. As it is mentioned, the control parameters values have been adjusted after several tests (Tab. 4). 
Table 3. [10] Standard size capacitors and their prices/kVAr

\begin{tabular}{lccccccccc}
\hline Index $(\mathrm{J})$ & 1 & 2 & 3 & 4 & 5 & 6 & 7 & 8 & 9 \\
$(\mathrm{kVAr})$ & 150 & 300 & 450 & 600 & 750 & 900 & 1050 & 1200 & 1350 \\
$(\$ / \mathrm{kVAr})$ & 0.5 & 0.35 & 0.253 & 0.22 & 0.276 & 0.183 & 0.228 & 0.17 & 0.207 \\
\hline Index $(\mathrm{J})$ & 10 & 11 & 12 & 13 & 14 & 15 & 16 & 17 & 18 \\
$(\mathrm{kVAr})$ & 1500 & 1650 & 1800 & 1950 & 2100 & 2250 & 2400 & 2550 & 2700 \\
$(\$ / \mathrm{kVAr})$ & 0.201 & 0.193 & 0.187 & 0.211 & 0.176 & 0.197 & 0.17 & 0.189 & 0.187 \\
\hline Index $(\mathrm{J})$ & 19 & 20 & 21 & 22 & 23 & 24 & 25 & 26 & 27 \\
$(\mathrm{kVAr})$ & 2850 & 3000 & 3150 & 3300 & 3450 & 3600 & 3750 & 3900 & 4050 \\
$(\$ / \mathrm{kVAr})$ & 0.183 & 0.180 & 0.195 & 0.174 & 0.188 & 0.170 & 0.183 & 0.182 & 0.179 \\
\hline
\end{tabular}

Table 4. Control parameters (10 buses network)

\begin{tabular}{cl}
\hline Control parameters Definition \\
\hline$n_{p} / 100$ & Individuals number in a population \\
$n_{\text {gen }} / 100$ & maximal number of generations \\
$T_{\text {div }} / 0.66$ & Balance rate \\
$J_{\max } / 27$ & Maximal index of possible sizes \\
$0.9<V(\mathrm{pu})<1.1$ & Voltage boundary \\
\hline
\end{tabular}

Table 5. Results and comparisons (10 buses network)

\begin{tabular}{|c|c|c|c|c|c|c|}
\hline & \multirow{2}{*}{$\begin{array}{c}\text { Before } \\
\text { (without } \\
\text { compensation) }\end{array}$} & \multicolumn{5}{|c|}{ After Compensation } \\
\hline & & $\begin{array}{c}\text { NHS [6] } \\
\text { "2002" }\end{array}$ & $\begin{array}{c}\text { PSO [7] } \\
\text { "2006" }\end{array}$ & Plant 1 & $\begin{array}{l}\text { Growth [3] } \\
2008 "\end{array}$ & $\begin{array}{c}\text { Proposed } \\
\text { method }\end{array}$ \\
\hline Total power losses $(\mathrm{kW})$ & 783.78 & 688.73 & 684.38 & & 694.39 & 681.68 \\
\hline Reduction of losses (kW) & - & 95.04 & 99.4 & & 89.38 & 102.09 \\
\hline $\begin{array}{l}\text { Location } \\
\text { and optimal size } \\
\text { (kVAr) }\end{array}$ & - & $\begin{array}{rr}5 & 1200 \\
4 & 1800 \\
9 & 450 \\
8 & 300\end{array}$ & $\begin{array}{rr}1 & 1800 \\
2 & 1650 \\
3 & 1200 \\
4 & 1800 \\
5 & 1200 \\
6 & 450 \\
8 & 450 \\
9 & 450 \\
\end{array}$ & $\begin{array}{l}5 \\
4 \\
8 \\
9\end{array}$ & $\begin{array}{r}1200 \\
1200 \\
200 \\
407\end{array}$ & $\begin{array}{rr}2 & 3450 \\
3 & 750 \\
4 & 3450 \\
6 & 750 \\
9 & 750\end{array}$ \\
\hline Total compensation (kVAr) & - & 3750 & 9000 & & 3007 & 9150 \\
\hline Vmin $\mathrm{pu}$ ) & 0.837497 & 0.8802 & 0.9000 & & .8733 & 0.9000 \\
\hline Vmax (pu) & 0.992901 & 0.9960 & 1.0030 & & .9954 & 1.0052 \\
\hline Annual cost (\$) & 131676.6 & 116466 & 116717 & & 7284.3 & 116442.1 \\
\hline Annual profit (\$) & - & 15210.5 & 14959.5 & & 392.2 & 15234.5 \\
\hline
\end{tabular}

Table 6. Control parameters (IEEE 34 buses network)

\begin{tabular}{ll}
\hline Control parameters & Definition \\
\hline$n_{p} / 80$ & Individuals number in a population \\
$n_{\text {gen }} / 100$ & maximal number of generations \\
$T_{\text {div }} / 0.6$ & Balance rate \\
$J_{\max } / 20$ & Maximal index of possible sizes \\
$0.95<V(\mathrm{pu})<1.05$ & Voltage boundary \\
\hline
\end{tabular}

The program using the proposed algorithm was performed under MATLAB. The obtained optimum solution is compared with recent studies in Tab. 5 .

\subsection{0 buses test network}

The optimization of the size, number and capacitors locations has been done in one level. We have got 5 capacitors with total compensation equal to $9150 \mathrm{kVAr}$ and their optimum locations have lead the reduction of active power losses of $102.09 \mathrm{~kW}$ and annual profit of $15234.52 \$$. The voltages in different buses before compensation were in boundary $0.8374 \mathrm{pu}<V<0.9929 \mathrm{pu}$ and after compensation the voltages are improved and situated in boundary $0.9000 \mathrm{pu}<V<1.90052 \mathrm{pu}$.

\subsection{IEEE 34 buses test network}

This test network [13] is a no homogeneous $11 \mathrm{kV}$ radial distribution network with ramification. The network data are given in the Tab. 6 .
Also, for this network we got better optimization in comparison with other methods. The results show that with 3 capacitors, one with size $1050 \mathrm{kVAr}$ and two with size $750 \mathrm{kVAr}$, located in buses 8,18 and 25 permit to reduce the total power losses by $60.38 \mathrm{~kW}$ and annual profit equals to $9491.9 \$$. And the voltages in different buses before compensation were in boundary $0.9491 \mathrm{pu}<$ $V<0.9941 \mathrm{pu}$. After compensation, the voltages are in the boundary $0.9506 \mathrm{pu}<V<0.9952 \mathrm{pu}$.

\section{CONCLUSION}

Through the comparison between the obtained results and previous results presented by different authors, we notice clearly that the proposed new technique have given a best and further optimization of numbers, sizes and locations of the shunt capacitors. Consequently, we get further minimization of the annual cost of the active power losses and more improvement of different buses voltages. The buses were classified on decreasing sensitive order in function with their contributions in total losses in the network. The attribution of the size is depending on sensitive order of each emplacement in the initial population. The evolution process is based on the intermediary recombination of individual chosen in function of the objectives. The presented new technique is full of promises. 
Table 7. Results and comparisons (IEEE 34 buses network)

\begin{tabular}{|c|c|c|c|c|c|}
\hline & \multirow{2}{*}{$\begin{array}{c}\text { Before } \\
\text { (without } \\
\text { compensation) }\end{array}$} & \multicolumn{4}{|c|}{ After Compensation } \\
\hline & & $\begin{array}{c}\text { Fuzzy \& real } \\
\text { coded genetic [4] } \\
\text { "2008" }\end{array}$ & $\begin{array}{r}\text { PSO [8] } \\
\text { "2007" }\end{array}$ & $\begin{array}{l}\text { Plant Growth [3] } \\
\text { "2008" }\end{array}$ & $\begin{array}{l}\text { Proposed } \\
\text { method }\end{array}$ \\
\hline Total power losses $(\mathrm{kW})$ & 221.72 & 168.95 & 168.95 & 169.14 & 161.33 \\
\hline Reduction of losses (kW) & - & 52.76 & 52.82 & 52.57 & 60.38 \\
\hline $\begin{array}{l}\text { Location and optimal size } \\
\text { (kVAr) }\end{array}$ & - & $\begin{array}{ll}19 & 683 \\
20 & 145 \\
21 & 144 \\
22 & 143 \\
23 & 143 \\
24 & 143 \\
25 & 228\end{array}$ & $\begin{array}{ll}18 & 761 \\
21 & 803 \\
19 & 479\end{array}$ & $\begin{array}{rr}18 & 1200 \\
21 & 639 \\
19 & 200\end{array}$ & $\begin{array}{lr}8 & 1050 \\
18 & 750 \\
25 & 750\end{array}$ \\
\hline Total compensation (kVAr) & - & 1629 & 2063 & 2039 & 2550 \\
\hline $\operatorname{Vmin}(\mathrm{pu})$ & 0.9417 & 0.9491 & 0.9496 & 0.9492 & 0.9506 \\
\hline$V \max (\mathrm{pu})$ & 0.9941 & 0.9948 & 0.9950 & 0.9950 & 0.9952 \\
\hline Annual cost (\$) & 37249.55 & 29070.60 & 28819.80 & 28931.52 & 27757.64 \\
\hline Annual profit $(\$)$ & - & 8178.95 & 8429.75 & 8318.03 & 9491.90 \\
\hline
\end{tabular}

\section{REFERENCES}

[1] SALEM, A. : Différentes Techniques de Planification de l'Energie Réactive dans les Réseaux Electriques, Thèse de doctorat. Ecole nationale polytechnique d'Alger 29 avril 2008.

[2] MENDES, A. : An Evolutionary Approach for Capacitor Placement in Distribution Networks, R. Prof. Dr. Edgard Atra 644 13105-666 Campinas SP - Brazil - 2008.

[3] RAO, R. S.-NARASIMHAM, S. V. L.: Optimal Capacitor Placement in a Radial Distribution System using Plant Growth Simulation Algorithm, International Journal of Electrical and Electronics Engineering (2008).

[4] REDDY, M. D.-REDDY, V.: Optimal Capacitor Placement using Fuzzy and Real Coded Genetic Algorithm for Maximum Savings, Journal of Theoretical and Applied Information Technology 2005-2008 JATIT.

[5] DARLING, G. : Capacitor Placement Replacement and Control in Large-Scale Distribution Systems by a GA-Based Two-Stage Algorithm, IEEE Transactions on Power Systems 12 No. 3 (Aug 1997).

[6] MEKHAMER, S. F.-El-HAWARY, M. E.-SOLIMAN, S. A.-MOUSTAFA, M. A.-MANSOUR, M. M. : New Heuristic Strategies for Reactive Power Compensation of Radial Distribution Feeders, IEEE Transactions on Power Delivery 17 No. 4 (Oct 2002).

[7] KHALIL, T. M.-YOUSSEF, H. K. M.-AZIZ, M. M. A. : A Binary Particle Swarm Optimization for Optimal Placement and Sizing of Capacitor Banks in Radial Distribution Feeders with Distorted Substation Voltages, AIML 06 International Conference, 13-15 June 2006, Sharm El Sheikh, Egypt.

[8] PRAKASH, K.-SYDULU, M.: Particle Swarm Optimization Based Capacitor Placement on Radial Distribution Systems, IEEE Power Engineering Society General Meeting, 2007, pp. 1-5.

[9] DAS, D. : Reactive Power Compensation for Radial Distribution Networks using Genetic Algorithms, Electric Power and Energy Systems 24 (2002), 573-581.

[10] BAGHzOUZ, Y.-ERTEM, S.: Shunt Capacitor Sizing for Radial Distribution Feeders with Distorted Substation Voltages, IEEE Trans. Power Delivery 5 (Apr 1990), 650-657.

[11] MEKHAMER, S. F. et al : Load Flow Solution of Radial Distribution Feeders: a New Contribution, Electric Power Components and Systems 24 (2002).
[12] BAGHzOUZ, Y.-ERTEM, S.: Shunt Capacitor Sizing for Radial Distribution Feeders with Distorted Substation Voltages, IEEE Trans Power Delivery 5 (1990), 650-657.

13] CHIS, M.-SALAMA, M. M. A.-JAYARAM, S.: Capacitor Placement in Distribution System using Heuristic Search Strategies, IEE Proc-Gener, Transm, Distrib 144 No. 3 (May 1997), $225-230$.

Received 23 May 2010

Ali Elmaouhab was born in 1960 at Algiers, Algeria. He received the Eng degree from Annaba university, Algeria in 1985 and Mphil degree from Queen Mary college, university of London, England in electrical engineering in 1988. He is preparing his Phd at Industriel and Electrical Systems Research Laboratory (LSEI). He is currently lecturer at university of Houari boumediene of science and technology of Algiers, Algeria. Field of interest integration and impact of wind generator in electrical network.

Mohamed Boudour was born in Algiers, Algeria, in 1969. He received the BSc, MSc and the PhD degrees in Electrical Engineering from the Polytechnic Institute of Algiers in 1991, 1994 and 2004 respectively. Since January 1993, he has been with the University of Sciences and Technology Houari Boumediene (USTHB) of Algiers as a teacher and researcher and a Fulbright Fellowship during 2005-2006 in the University of Washington (Seattle, USA). His main interests are Power Systems Stability, Security assessment, Control, Optimization, Protection, Application of intelligent and metaheuristics in Electrical Engineering and has published more than 80 papers in the field. He is now Professor in Electrical Engineering at USTHB and the Director of the Industrial and Electrical Systems Research Laboratory (LSEI) since 2007.

Rabah Gueddouche received the BSc diploma in electrical engineering from university of Houari Boumediene for science and technology of Algiers. He is preparing his MSc diploma at Industriel and Electrical Systems Research Laboratory (LSEI). 